\title{
Estilo motivacional do professor e a motivação extrínseca dos estudantes
}

\section{The teacher's motivational style and the students' extrinsic motivation}

\author{
Amélia Carolina Terra Alves Machado후 Sueli Edi Rufini Guimarães²; \\ José Aloyseo Bzuneck ${ }^{3}$
}

\begin{abstract}
Resumo
O ambiente de sala de aula é apontado como fator determinante do interesse dos alunos com conteúdos escolares. Nesse contexto, o estilo motivacional do professor é considerado uma das principais influências na motivação dos estudantes. A literatura aponta para uma predominância de motivação extrínseca em relação à escola em decorrência, principalmente, das ações do professor em sala de aula. Neste trabalho serão apresentadas, na perspectiva da Teoria da Autodeterminação, as implicações do estilo motivacional do professor para o envolvimento de alunos. Além disso, serão descritos os procedimentos e resultados de uma etapa do trabalho de validação da versão brasileira de um questionário de avaliação do estilo motivacional do professor (Problems in Schools). Com base na literatura da área, foram elaborados itens de avaliação do estilo motivacional e esse instrumento inicial foi apresentado a um grupo de 10 professores. Neste artigo são apresentadas as análises das entrevistas realizadas após o contato com o instrumento.
\end{abstract}

Palavras-chave: Teoria da autodeterminação. Estilo motivacional. Motivação extrínseca.

\section{Abstract}

The classroom environment is considered as a key factor for the students' interest regarding school contents. In this context, the teacher's motivational style is considered as one of the main influences on students' motivation. Literature points to a predominance of extrinsic motivation in relation to the school due to the teacher's actions in the classroom. In this work, the implications of the teacher's motivational style for the involvement of students will be presented, based on the self-determination theory. Moreover, it will be described the procedures and results of a stage of the validation work of the Brazilian version of an evaluation questionnaire of the teacher's motivational style (Problems in School). Based on the literature of the area, assessment items of the teacher's motivational style were elaborated and this first instrument was shown to a group of 10 teachers. The analyses of interviews carried out after the first contact with this instrument, are also shown in this article.

Key words: Self-determination theory. Motivational style. Extrinsic motivation.

\footnotetext{
${ }^{1}$ Graduanda em Pedagogia. Universidade Estadual de Londrina, UEL, Brasil. Bolsista do: Conselho Nacional de Desenvolvimento Científico e Tecnológico, CNPq.

${ }^{2}$ Prof $^{a}$. Dr. ${ }^{a}$ da Universidade Estadual de Londrina, Centro de Educação Comunicação e Artes.

${ }^{3}$ Prof $^{\circ}$. Dr. ${ }^{\circ}$ da Universidade Estadual de Londrina, Centro de Educação Comunicação e Artes, Departamento de Educação. Campus Universitário- Londrina, PR.
} 


\section{Introdução}

O tema motivação tem sido amplamente discutido na atualidade, por que sua ausência representa queda de investimento pessoal nas tarefas propostas no ambiente escolar. Segundo Bzuneck (2001), motivação é aquilo que move uma pessoa a realizar uma determinada ação e, de acordo com as atuais abordagens psicológicas que se dedicam ao assunto, ora a motivação pode ser entendida como um processo, ora como um fator psicológico.

O contexto de sala de aulaé um ambiente particular para o estudo da motivação, visto que difere de outras situações sociais e daquelas criadas experimentalmente em laboratórios. A escola é um ambiente social em que situações de fracassos podem gerar humilhações públicas, a frequiência é obrigatória, os conteúdos curriculares são impostos, sem considerar a opinião ou interesses do aluno, as classes possuem dezenas de alunos e, principalmente, incidem notas sobre o trabalho dos alunos. Esses fatores tendem a fazer com que os alunos foquem sua atenção sobre as exigências necessárias ao êxito, ou seja, aquelas sobre as quais sua performance é avaliada (BROPHY, 1999).

Os professores também enfrentam dificuldades para motivar seus alunos, visto que os conteúdos são compulsórios, nem sempre são agradáveis, não existe a possibilidade de trabalhar de acordo com as necessidades ou interesses individuais do aluno e objetivos fixados pelo currículo devem ser cumpridos em prazos determinados. No entanto, os professores podem proporcionar oportunidades de escolha e autonomia, organizando o ensino e respondendo aos alunos de forma menos controladora.

Em sala de aula, a motivação responde a determinados efeitos, imediatos ou finais. Os efeitos imediatos correspondem ao envolvimento ativo do aluno nas tarefas, empenhando esforço para aprender; os efeitos finais correspondem a tudo que foi construído, as habilidades adquiridas, ou seja, os produtos da aprendizagem.

Segundo Brophy (1999), os educadores devem enfatizar a motivação para o aprendizado, incentivar o processamento profundo de informações, em oposição à motivação para o desempenho, que se refere à demonstração de habilidades adquiridas, a performance.

Ainda segundo o autor, alunos que possuem motivação para aprender não necessariamente acham todas as tarefas interessantes, mas percebem-nas como significativas e buscam retirar delas o máximo de proveito. Alunos desmotivados, por outro lado, estudam muito pouco, com frequiência são desatentos e provocam situações de indisciplina na sala de aula. No entanto, nem sempre é fácil verificar se tais comportamentos são devido a desmotivação do aluno e, para que se identifique tal problema, deve-se considerar dois aspectos: quantitativos e qualitativos.

Os dados quantitativos falam sobre a intensidade da motivação. Brophy (1999) afirma que o nível ótimo não está nos extremos, alto ou baixo, mas sim no nível motivacional adequado ao nível de exigência da tarefa. Os qualitativos dizem respeito às razões motivacionais, extrínsecas e intrínsecas. Quando a motivação é distorcida, vem acompanhada de possíveis emoções negativas como medo do fracasso, alta ansiedade, frustração, irritação e decréscimo na qualidade das tarefas escolares.

Bzuneck (2001) faz duas especificações sobre o problema motivacional. Primeiro, a respeito das generalizações, apontando que o aluno desmotivado não é necessariamente sem motivação para todas as atividades escolares. Segundo, que os problemas motivacionais atendem a uma gradação, um continnum, dos simples, por exemplo, o aluno que tem antipatia pelo professor e, por isso, não dá atenção a sua aula, aos complexos, o aluno que não vai à aula, por causa da antipatia ao professor.

Visando a apontar as principais tendências contemporâneas no estudo da motivação, Bzuneck (2001) descreve as características das principais correntes. Para isso, cita três modelos organizacionais, propostos para a compreensão dos principais focos de atenção das abordagens mais recentes que tratam da motivação. 
O primeiro modelo, proposto por Graham e Weiner (1996), enfatiza a prevalência das abordagens cognitivas, citando, como exemplo, os estudos sobre autovalorização, atribuições causais, crenças de autoeficácia, desamparo adquirido e pensamentos acerca de objetivos ou metas que se desejam atingir. Os autores salientam a pesquisa em torno das metas de realização, principalmente as metas aprender e de performance.

Pintrich e De Groot (1990), propondo o segundo modelo, ressaltam os estudos da motivação na linha de expectativa - valor, sendo expectativa a crença da pessoa quanto a sua capacidade de realizar uma tarefa, e valor o grau de importância atribuído a tarefa. Outro componente considerado neste modelo é o afetivo, ou seja, as reações emocionais frente à tarefa.

A análise feita por Stipek (1996), no terceiro modelo descrito por Bzuneck (2001), focalizou, nos estudos motivacionais, quatro tópicos relevantes, para o contexto escolar: o reforçamento positivo, as cognições, os valores e as metas de realização. Bzuneck (2001) conclui que as atuais tendências do estudo salientam os componentes cognitivos ligados ao self.

O professor do século XXI é encarado como um profissional diariamente instigado a fazer julgamentos e tomar decisões em relação à escola e à sala de aula (GUIMARÃES, 2003), por isso suas crenças e pensamentos influenciam a motivação gerada no ambiente de ensino.

A motivação do aluno resulta de interações entre características pessoais e fatores contextuais. $\mathrm{O}$ professor que encontra alunos desmotivados ou dependentes de recompensas externas deve proporcionar tarefas mais desafiadoras e diminuir as verbalizações que enfatizem tais consequiências, reorientando - os para a meta aprender, desenvolvendo a motivação para o domínio dos conteúdos e para o crescimento intelectual contínuo.

O papel do professor em relação à motivação dos estudantes teria duas funções: a remediadora, que seria recuperar alunos desmotivados e reorientar os de motivação distorcida; a preventiva e permanente, implementando e mantendo otimizada a motivação para aprender (BZUNECK, 2001).

Tendo em vista a relevância dos estudos a cerca da motivação no ambiente escolar, este trabalho focalizou, sob uma das vertentes teóricas relativas ao tema, a Teoria da Autodeterminação (DECI; RYAN, 2000), a motivação extrínseca e suas implicações.

\section{Teoria da Autodeterminação}

A teoria da autodeterminação é voltada para a compreensão das questões relacionadas com a motivação. Propõe que todo ser humano tem tendências naturais para o crescimento e necessidades psicológicas inatas que lhe oferecem uma base para a motivação autônoma e para o desenvolvimento psicológico saudável (REEVE; DECI; RYAN, 2004), procurando relacioná-los com as condições sociais que o rodeiam. Dois tipos de motivação são propostos, a motivação intrínseca, na qual a atividade é o fim em si mesma, com resultados positivos em termos de persistência, criatividade, aprendizagem duradoura, entre outros, e a motivação extrínseca, cujo envolvimento na atividade é um meio para obter resultados externos.

Sendo a Teoria da Autodeterminação uma macro teoria da motivação humana (REEVE; DECI; RYAN, 2004), foram elaboradas a partir dela quatro teorias menores: a) A teoria das Necessidades Básicas, apontando três necessidades psicológicas cruciais para o desenvolvimento da motivação intrínseca, sendo elas, a experiência de pertencer, de autonomia, e de competência; b) A teoria da Integração Organísmica, que propõe que as regulações externas podem ser internalizadas, podendo gerar uma motivação autoregulada ; c) A teoria da Orientação de Causalidade, que se refere às orientações persistentes da personalidade e sua influência sobre a qualidade da motivação dos indivíduos; d) Teoria da Avaliação Cognitiva, que estuda como a oferta de recompensas as vezes apóiam e em outras atrapalham a motivação intrínseca . 
Como base para as posteriores análises, focalizaremos duas teorias, a da Teoria da Avaliação Cognitiva e a da Teoria da Integração Organísmica.

\section{Teoria da Avaliação Cognitiva}

Esta teoria focaliza os efeitos dos eventos externos sobre a motivação intrínseca. Quando o ambiente externo ameaça a satisfação das necessidades psicológicas básicas do indivíduo, a motivação intrínseca poderá ser prejudicada.

Os eventos externos, segundo essa teoria, podem ter dois aspectos funcionais: um é o controlador e o outro informacional. $\mathrm{O}$ aspecto controlador é aquele que pressiona o aluno a ter um determinado comportamento ou a atingir um resultado imposto. Estes eventos prejudicam a motivação intrínseca porque ameaçam a satisfação da necessidade de autonomia. Sendo assim, ao perceber que está sob uma situação altamente controlada, o aluno tende a diminuir sua motivação intrínseca.

$\mathrm{O}$ aspecto informacional, por sua vez, é aquele que, de modo não controlador, transmite algum tipo de feedback (positivo ou negativo). Tende a favorecer a motivação intrínseca, quando oferece afirmações sobre a competência e a diminuir quando as informações apontam para a incompetência da pessoa para realizar aquela atividade específica. Um aspecto importante a ser observado na Teoria da Avaliação Cognitiva é a possibilidade de predição do nível de motivação, dependendo do ambiente interpessoal no qual estes eventos externos são administrados, controlador ou informacional.

As recompensas externas, nessa linha de análise, poderiam representar os dois aspectos, dependendo da situação. Desse modo, os resultados de sua implementação em situações de aprendizagem poderiam ser negativos, ao contrário do aumento motivacional previsto. Estudiosos afirmam que a opção pela estratégia de oferecer recompensas em troca de algo tem sido amplamente utilizada na sociedade. Segundo Newby (1991) sobre o uso de recompensas "ela seria de simples implementação, principalmente em situações de sala de aula".

Grande parte desta educação mediante "barganhas" deve-se, de acordo com Salisbury Glennon (1999), à crença que os professores têm de que a única possibilidade de intervenção na motivação dos alunos se dá por meio das recompensas e das pressões externas.

Os resultados de inúmeros estudos, realizados nos últimos 30 anos, indicam que a motivação intrínseca é prejudicada nas seguintes condições: no caso de recompensas materiais ou concretas, quando uma recompensa é oferecida com um aspecto controlador, caso seja esperada pela pessoa durante a execução da tarefa, se são contingentes ao envolvimento na tarefa ou quando são oferecidas a uma pessoa que faria uma atividade de qualquer modo. Já as recompensas verbais, na avaliação das pesquisas acerca do tema, tiveram um efeito mais ameno e até mesmo de promoção da motivação intrínseca (LEPPER; HENDERLONG, apud SANSONE; HARACKIEWICZ, 2000; LEPPER; HENDERLONG; IYENGAR, 2005)

Alguns pesquisadores apontam quatro estratégias para que o impacto das recompensas externas seja menos prejudicial à motivação intrínseca: devem ser oferecidas de modo não contingente ao envolvimento e desempenho na tarefa; seu uso de forma inesperada pode influenciar positivamente a motivação intrínseca; as recompensas sociais são menos lesivas do que as materiais e as recompensas que apóiam e reforçam o senso de competência beneficiam a motivação (LEPPER; HENDERLONG, apud SANSONE; HARACKIEWICZ, 2000; LEPPER; HENDERLONG; IYENGAR, 2005).

\section{Teoria da Integração Organísmica}

As pesquisas atuais têm-se direcionado principalmente ao estudo da motivação intrínseca deixando, de certa maneira, pouco aprofundada a motivação extrínseca.

Segundo Deci e Ryan (2000), motivação extrínseca é aquela em que o indivíduo age em 
resposta a algo externo à atividade, ou seja, trabalha para receber recompensas, elogios, reconhecimento ou para demonstrar competência naquela atividade.

Analisando o contexto escolar, é complexo dizer em qual situação a motivação extrínseca não exista. Com efeito, o modelo de escola que se tem aponta para este tipo de motivação, realizando atividades que avaliam a performance dos alunos e atribuem recompensas a elas.

É importante ressaltar que não é tão simples diferenciar a motivação intrínseca da extrínseca. Podemos observar em diversas situações motivadas de modo extrínseco como, por exemplo, no trabalho, em sala de aula, níveis diferentes de envolvimento.
Nos últimos anos, o estudo desses padrões culminou na elaboração da Teoria da Integração Organísmica, uma das quatro mini teorias que compõe a Teoria da Autodeterminação. Propõe-se um continuum de desenvolvimento da regulação externa, caminhando de um extremo de desmotivação (ausência total de regulação) até um outro de motivação intrínseca (regulação totalmente interna), tendo como intermediários quatro níveis de motivação extrínseca, como demonstrado na figura 1 . O fator determinante desse desenvolvimento seria a autodeterminação, isto é, a percepção pessoal de ter interiorizadas as regulações externas.

\begin{tabular}{|c|c|c|c|c|c|c|}
\hline \multirow{2}{*}{$\begin{array}{l}\text { Comportamento } \\
\text { Motivação }\end{array}$} & \multicolumn{2}{|c|}{$\begin{array}{l}\text { Ausência de } \\
\text { determinação }\end{array}$} & \multicolumn{4}{|c|}{ Autodeterminado } \\
\hline & $\begin{array}{l}\text { Ausência } \\
\text { de } \\
\text { motivação }\end{array}$ & & \multicolumn{3}{|c|}{ Motivação Extrínseca } & $\begin{array}{l}\text { Motivação } \\
\text { Intrínseca }\end{array}$ \\
\hline $\begin{array}{l}\text { Estilos } \\
\text { reguladores }\end{array}$ & $\begin{array}{l}\text { Sem } \\
\text { regulação }\end{array}$ & $\begin{array}{c}\text { Regulação } \\
\text { externa }\end{array}$ & $\begin{array}{l}\text { Regulação } \\
\text { introjetada }\end{array}$ & $\begin{array}{l}\text { Regulação } \\
\text { identificada }\end{array}$ & $\begin{array}{c}\text { Regulação } \\
\text { integrada }\end{array}$ & $\begin{array}{c}\text { Regulação } \\
\text { intrínseca }\end{array}$ \\
\hline $\begin{array}{l}\text { Locus de } \\
\text { causalidade } \\
\text { percebido }\end{array}$ & impessoal & externo & Algo externo & Algo interno & interno & interno \\
\hline $\begin{array}{l}\text { Processos } \\
\text { reguladores }\end{array}$ & $\begin{array}{l}\text { Ausência } \\
\text { de } \\
\text { intenção, } \\
\text { desvaloriza } \\
\text { ção, falta } \\
\text { de controle. }\end{array}$ & $\begin{array}{l}\text { Submissão, } \\
\text { recompensas } \\
\text { externas e } \\
\text { punições. }\end{array}$ & $\begin{array}{l}\text { Autocontrole, } \\
\text { ego } \\
\text { envolvimento } \\
\text { recompensas } \\
\text { internas e } \\
\text { punições. }\end{array}$ & $\begin{array}{l}\text { Importância } \\
\text { pessoal, } \\
\text { valorização } \\
\text { consciente. }\end{array}$ & $\begin{array}{l}\text { Concordância, } \\
\text { consciência, } \\
\text { síntese com o } \\
\text { eu. }\end{array}$ & $\begin{array}{l}\text { Interesse, } \\
\text { prazer e } \\
\text { satisfação } \\
\text { inerente. }\end{array}$ \\
\hline
\end{tabular}

Quadro 1 - Continuum de autodeterminação, tipos de motivação com os seus loci de causalidade e processos correspondentes

Fonte: Reeve, Deci e Ryan (2004) 
Seus níveis seriam: regulação externa, regulação introjetada, regulação identificada e regulação integrada.

\section{Regulação externa}

A regulação externa é o nível de menor autodeterminação da motivação extrínseca. A pessoa que age por regulação externa, focaliza apenas os benefícios que a situação pode lhe trazer. Um exemplo disso seria uma criança que arruma a cama para poder assistir televisão. A atenção dela esta no fim, e não no processo.

\section{Regulação introjetada}

Indivíduos com este tipo de regulação agem movidos por sentimentos de culpa por seu comportamento ou por receio de romper com o grupo. Apesar de ser entendida como algo interno, a regulação introjetada ainda precisa de estímulos externos, sendo que estes não são necessariamente concretos. É considerada pouco estável, mas, mesmo assim, já é um avanço em relação ao nível anterior. Um exemplo dessa regulação do comportamento é a pessoa que sabe que cigarro faz mal, mas só para agradar os amigos quando está na turma fuma também.

\section{Regulação Identificada}

Na regulação identificada, o indivíduo sente uma atração pessoal por um determinado comportamento ou pelas pessoas que o apresentam e acreditam nele. Este nível já é um pouco mais estável, o comportamento resultante ainda não é autônomo, mas o interesse inicial sim. Gostar de matemática porque o professor é simpático e acreditar que o que ele pensa é interessante, pode ser um exemplo desta regulação.

\section{Regulação Integrada}

Corresponde ao nível mais autodeterminado do continnum de desenvolvimento da autodeterminação, relativo à motivação extrínseca. Nele, os estímulos externos são encarados como fonte e apoio para realização de tarefas. O comportamento resultante é praticamente similar ao da motivação intrínseca, ou seja, o indivíduo despende esforço, persistência, criatividade e processa as informações de modo profundo. Não existe coerção para regular o comportamento, as regulações externas são internalizadas, no entanto, a regra externa ainda está presente, ou seja, a pessoa não realizaria a atividade caso não recebesse algo em troca. Por exemplo, um médico que tem paixão por sua profissão, trabalha em um hospital e recebe um salário por seu trabalho, provavelmente se ele parar de receber o salário ele irá parar de trabalhar naquele hospital, mas não deixará de ter paixão pela medicina.

Os dois últimos níveis da motivação extrínseca muito se assemelham com a motivação intrínseca, pois já valorizam uma iniciativa interna em relação a uma determinada atividade. Na escola, nem sempre é possível proporcionar um ambiente que estimule a motivação intrínseca do aluno, mas, a promoção das formas auto - reguladas de motivação, as regulações identificada e integrada, já é um grande passo na direção de uma prática educativa menos controladora.

\section{Estilo Motivacional do Professor}

Cada professor possui uma maneira de encarar o seu ambiente de trabalho, seus alunos, e sua prática pedagógica. Muitos estudos têm sido realizados, questionando a relação desta prática pedagógica com a motivação do aluno. De acordo com Tollefson (2000), "podem surgir conflitos entre professores e alunos em relação às causas do fracasso destes últimos, com conseqüência tanto para a ação docente como para a motivação dos alunos". Entre as possíveis razões destes conflitos, a autora sugere que os alunos podem atribuir seu baixo envolvimento a fatores externos como a dificuldade do conteúdo, as aulas são desinteressantes, o professor é chato ou não possuem o material necessário para estudar. Os professores, neste caso, resistiriam à crítica feita ao seu trabalho, ressaltando que os alunos são desinteressados e por isso não alcançam as metas 
estabelecidas, podendo muitas vezes deixar de se empenharem em tornar a sua disciplina um conhecimento de interesse do aluno.

Tollefson (2000) ainda propõe que uma forma de resolver estes conflitos é fortalecer as crenças de auto-eficácia dos professores, principalmente com situações em que os alunos obtiveram êxito. Para isso, os professores deveriam aprender estratégias eficazes de trabalho em sala de aula, a forma de realizar adaptações curriculares para atender a diversidade de interesses, ritmos e conhecimentos dos alunos e, finalmente, criar um ambiente que facilite $o$ bom desempenho de todos.

Os estudos acerca do senso de eficácia dos professores intensificaram-se nos últimos anos. Inicialmente, a preocupação era apenas com as decisões que os professores tomavam em sala de aula, notou-se, no entanto, que este conceito era muito limitado para representar a atividade mental destes (GUIMARÃES, 2003). Com o fortalecimento das abordagens cognitivistas da psicologia, o foco de análise recaí sobre as reflexões e crenças que o professor possui.

O senso de eficácia no ambiente escolar seria a crença que o professor tem na sua capacidade de influenciar o desempenho dos alunos para as atividades cotidianas. As pesquisas acerca do tema empregaram diversos instrumentos de auto - relato, sendo o primeiro elaborado com base na Teoria da Aprendizagem Social de Rotter (apud GUIMARÃES, 2003). A Teoria Sócio Cognitiva de Albert Bandura,que propunha o constructo de auto-eficácia, revelou-se produtivo nessa temática. Segundo Bandura (apud AZEVEDO 1997, p.76) "A auto-eficácia percebida refere-se a crença nas próprias capacidades de executar cursos de ação exigidos para produzir determinadas realizações".

Na perspectiva da Teoria da Autodeterminação, o estilo motivacional do professor é considerado uma característica de personalidade, sendo, no entanto, suscetível a influências do contexto social como, por exemplo, o número de alunos por sala, a fase de desenvolvimento dos alunos, as interações entre o professor e a equipe pedagógica ou direção da escola. Além disso, características pessoais do professor como gênero, idade, tempo experiência no magistério, também seriam importantes fontes de influência.

Alguns professores tenderiam, então, a adotar um estilo motivacional controlado e outros um estilo mais voltado à promoção de autonomia nas interações com seus alunos. Pesquisas utilizando esse constructo revelaram relações positivas entre estilos motivacionais promotores de autonomia com a motivação intrínseca dos estudantes (GUIMARÃES; BORUCHOVITCH, 2004).

Com base no referencial teórico apresentado, foi desenvolvido um estudo de adaptação e levantamento das propriedades psicométricas de um instrumento de avaliação do estilo motivacional de professores, elaborado por Deci et al. (1981). O estudo mais amplo contou com a participação de 1296 professores do ensino fundamental e médio de diversas regiões do Brasil. Itens do instrumento original, já validados em estudo anterior (GUIMARÃES; BZUNECK, 2006; BORUCHOVITCH; BZUNECK, 2004), compuseram a versão investigada, além de novos itens elaborados a partir da literatura. Como avaliadores, quatro pesquisadores da área receberam para análise a definição dos constructos e as propostas de itens para sua avaliação e foram instruídos a escolher aqueles que pareciam mais relacionados ao constructo indicado. Depois dessa seleção, uma versão preliminar do instrumento foi apresentada a um grupo de 10 professores para se verificar a adequação de linguagem e as interpretações sobre o conteúdo do teste. Neste artigo, é descrita uma das etapas desse trabalho, e são apresentadas as análises das entrevistas realizadas com os professores.

\section{Metodologia}

\section{Participantes}

Este estudo é parte de um estudo mais amplo de validação de uma escala de avaliação do estilo motivacional de professores, e contou com a 
participação de 10 professores do ensino fundamental e médio da rede pública e privada de ensino.

\section{Procedimentos}

Aos professores foi solicitado responder o questionário e, em seguida, foram feitas entrevistas acerca da compreensão total, parcial ou incompreensão acerca das histórias e dos itens. Além disso, foram colhidas sugestões dos professores sobre como melhorar a compreensão do questionário.

As entrevistas foram realizadas nas escolas, nas casas dos professores e na universidade, gravadas e posteriormente transcritas.

Lidas as entrevistas, as respostas dos professores foram organizadas em dois conjuntos: primeiro as histórias e segundo os itens. Nos dois casos, as respostas foram classificadas de acordo com o nível de compreensão: total, parcial; distorções; incompreensão; sugestões.

\section{Instrumento}

A avaliação do estilo motivacional de professores é um instrumento de auto - relato, composto de oito histórias envolvendo problemas cotidianos na interação entre crianças e adultos. Para cada história, o professor participante deve assinalar o seu grau de concordância (em escala likert de 7 pontos) em relação a quatro soluções para o problema apresentado, cada uma correspondendo a um estilo moticacional. Assim, 32 itens avaliam o estilo motivacional do professor, sendo eles: alto promotor de autonomia (AA), (cujo papel do professor é incentivar o aluno a buscar soluções autônomas para os seus problemas); moderado promotor de autonomia(MA), (o professor encoraja o aluno a ter empatia pelo sua forma de compreender, diagnosticar e resolver um problema); moderado controlador (MC) (o professor percebe uma solução e encoraja sua aplicação por recorrer ao senso interno de "obrigação" do aluno ou para o que os outros julgam correto); alto controlador (AC), (o professor identifica uma solução e por meio de estímulos extrínsecos direcionam os alunos a alcançarem o resultado que deseja). É neste último estilo que a regulação externa tem seu ápice, visto que o professor entende que o controle da sala só é possível mediante o uso de recompensas e pressões externas, criando um clima interpessoal de absoluto controle.

O levantamento das propriedades psicométricas da versão brasileira do questionário "Problems in Schools", adaptada e validada por Guimarães (2003), apresentou algumas limitações gerando a pesquisa aqui descrita. No estudo de 2003, com base na respectiva definição de cada estilo motivacional, notou-se a discrepância nas proposições oferecidas. Para as respostas moderadamente promotoras de autonomia, teoricamente espera-se que o professor encoraje o aluno a ter empatia pela sua forma de compreender as situações. No entanto, quando se averiguou a proposição referente a este estilo no questionário, observa-se um incentivo a comparação social. Por exemplo, no caso em que se quer modificar o comportamento de timidez de uma criança o questionário propõe no item 6D: encorajá-la a observar como as outras crianças relacionam-se e incentivá-la a unir-se a elas.

Além da discrepância entre o conceito e item elaborado, o estudo quantitativo para a validação do instrumento reafirmou essa inconsistência. Assim, foram feitas, para cada item excluído, quatro novas opções de afirmativas e apresentadas a quatro juízes. Eles deveriam optar pela afirmativa que julgassem ser mais coerente com o respectivo estilo motivacional. Se houvesse concordância, o item era aprovado, se não outra reformulação era feita.

\section{Resultados}

A partir das entrevistas realizadas com os professores, foram detectadas algumas distorções na elaboração das afirmativas e, em outros casos, os participantes fizeram sugestões para a melhoria da clareza dos itens. No item 1C (Nunca permitir que ele saia da sala de aula enquanto não tiver terminado as tarefas solicitadas), dois professores fizeram a sugestão de que deveria ser dado um castigo, ou uma punição coercitiva ao aluno. No item 1D (Contar para 
ele, que quando tinha sua idade, também não entendia a importância das aulas e tarefas, porém mais tarde passou a entender e teve de estudar mais para recuperar o tempo perdido), alguns professores disseram que só conversar com o aluno não adianta. No item 4C (Mostrar que você sabe o quanto o jogo de futebol é importante para ele, mas que acredita que ele saiba o quanto é importante escrever bem o português), um professor interpretou a afirmativa de escrever bem o português como sendo "que o aluno tinha que ir bem na escola", sugerindo a alteração da frase. Um professor em relação ao item $5 \mathrm{~A}$ (Conversaria com eles acerca de suas dificuldades demonstrando que acredito que se esforçarão para melhorar), entendeu que "A conversa é para descobrir o que não estão aprendendo para que se esforcem e melhorem" tendo uma compreensão parcial da questão. No item 6A (Dizer-lhe que deve aproximar-se dos colegas e elogia-la quando agir como você ensinou), um professor não compreendeu a proposição "não fica claro se é para falar com a aluna ou com os outros" sugerindo alteração para melhorar a clareza.

\section{Discussão e Conclusão}

A validação de instrumento de coleta de informação para uso em pesquisas é importante para que o pesquisador tenha um certo nível de confiança nos dados obtidos que servirão como base para as análises e conclusões de suas investigações. No caso do uso de instrumentos elaborados em outras culturas, além da tradução, adaptação e das análises estatísticas previstas, é crucial que se verifique a pertinência dos itens para a população que participará do estudo.

Van de Vijver e Hambleton (1996) salientavam alguns cuidados necessários para que trabalhos envolvendo avaliações interculturais, apresentem contribuições efetivas. Para os autores, a aplicação de um instrumento, em uma cultura diferente da qual este foi originalmente elaborado, exige mais do que simplesmente produzir um texto em outra língua, administrá-lo e, posteriormente, comparar seus resultados. O constructo em torno do qual o teste foi elaborado, a metodologia indicada para sua aplicação, o formato das respostas (escala likert ou questões de múltipla escolha) e as apresentações dos itens podem ter características que influenciarão as respostas dos participantes de uma outra cultura. Aquele constructo investigado e os comportamentos a ele vinculados podem não existir ou serem diferentes naquela cultura em particular. Para exemplificar, os autores comparam as relações entre pais e filhos ocidentais e chineses. Ser um bom filho, cuidar dos pais e tratálos bem são comportamentos com significado muito diferente para cada cultura. Um teste que busque avaliar tais padrões comportamentais necessitaria ser revisto substancialmente, talvez até sendo apontada a necessidade de elaboração de um novo instrumento.

Quanto à metodologia indicada para a administração de um instrumento, é preciso verificar se aquele grupo está familiarizado com o formato das questões ou com a própria situação de teste. Caso contrário, esse fator pode influenciar os resultados da avaliação e não ser percebido pelos pesquisadores, que poderão atribuir as diferenças nas respostas dos participantes a outras fontes de influência.

Finalmente, Van de Vijver e Hambleton (1996) ressaltam os cuidados exigidos para a tradução e adaptação dos itens dos testes. A pobreza das palavras, traduções incorretas, conteúdos dos itens não apropriados para aquela cultura podem, em conjunto ou isoladamente, influenciar as respostas dos participantes. Para superar esse problema, indicam metodologias mais sofisticadas para o trabalho de tradução e adaptação de instrumentos para a pesquisa intercultural. Uma primeira versão na língua do grupo a ser avaliado, seguida de back translation e de comparações com a versão original pode minimizar os problemas de linguagem. No caso do instrumento aqui estudado, no primeiro trabalho realizado (GUIMARÃES, 2003) essa técnica foi utilizada. Sendo uma metodologia relativamente simples é muito difundida, no entanto, não é suficiente para detectar as possíveis fontes de influências existentes no próprio constructo e na metodologia utilizada para a coleta 
de dados. Nesse caso, mais de uma aplicação do instrumento pode auxiliar na constatação de problemas a ele inerentes. Também são indicados procedimentos não-padronizados de coleta de dados como, por exemplo, solicitando que os participantes falem sobre a sua interpretação particular acerca das instruções para a realização do teste, sobre os conteúdos dos itens, sobre o formato das alternativas de respostas e sobre sua motivação para responder a avaliação. Estes cuidados adicionais podem oferecer uma oportunidade para a checagem da confiabilidade do instrumento para aquela cultura.

Esta última indicação dos mesmos autores fundamentou a presente ação no projeto de validação do instrumento.

Considerando um total de 8 histórias e 32 itens, o apontamento, por parte dos professores, de incompreensão em apenas um dos itens por parte de apenas um entrevistado, é um ótimo resultado. Além disso, as sugestões feitas pelos professores não indicaram necessidade de alteração, pois apenas referiam-se a preferência por um outro exemplo, não sendo substanciais para o conteúdo dos itens. As entrevistas mostraram ampla compreensão por parte dos professores, e conduziram à conclusão de que o instrumento "Problems in School", reformulado e adaptado à cultura brasileira, está coerente, e não precisa de novas modificações.

Diante disso, discute-se que, com a futura validação do questionário com os itens elaborados e, com o cuidado de verificar a interpretação por professores brasileiros deles e das as histórias contidas no teste, será possível ter disponível uma escala confiável de avaliação dos estilos motivacionais do professor para uso em pesquisas brasileiras. Com a possibilidade dessa mensuração, investigações poderão ser conduzidas, com o objetivo de conhecer como, por exemplo, um professor com estilo promotor de autonomia conduz suas atividades em sala de aula, como são seus alunos. Essas informações não só permitem um crescimento de conhecimentos na área como também podem servir como elementos para a formação de professores.

\section{Referências}

AZEVEDO, Mário. A teoria cognitiva social de Albert Bandura . Lisboa: Universidade de Lisboa, Faculdade de Ciências, 1997.

BORUCHOVITCH, E.; BZUNECK, J. A. (Org.). A Motivação do Aluno. Contribuições da Psicologia Contemporânea. 3.ed. Petrópolis: Vozes, 2004.

BROPHY, J. Motivating Students to Learn. Boston: McGraw Hill, 1999.

BZUNECK, J. A. A motivação do aluno: aspectos introdutórios. E. In: (Ed.). A motivação do aluno: Contribuições da psicologia contemporânea. Petrópolis:Vozes, 2001. p.9-36.

DECI, E. L.; RYAN, R. M. The "what" and "why" of goal pursuits: human needs and self-determination of behavior. Psychological Inquiry, Rochester, v.11, n.4, p.227-268, 2000.

DECI, E. L.; SCHWARTZ, A. J.; SHEINMAN, L.; RYAN, R. M. An instrument to assess adults'orientations toward control versus autonomy with children: reflections on intrinsic motivation and perceived competence. Journal of Educational Psychology, Arlington, v.73, n.5, p.642-650, 1981.

GRAHAM, S.; WEINER, B. Theories and principles of motivation. In: BERLINER, D. C.; CALFEE, R. C. (Eds.). Handbook of Educational Psychology. New York: Simon \& Schuster Macmillan, 1996. p.63-84.

GUIMARÃES, S. E. R. Avaliação do estilo motivacional do professor: Adaptação e validação de um instrumento. 2003. Tese (Doutorado em Educação) - Faculdade de Educação, Universidade Estadual de Campinas, Campinas.

GUIMARÃES, S. E. R.; BORUCHOVITCH, E. O Estilo Motivacional do Professor e a Motivação Intrínseca dos estudantes: Uma Perspectiva da Teoria 
da Autodeterminação. Psicologia: Reflexão e Crítica, Porto Alegre, v17, n.2, p.143-150, 2004.

GUIMARÃES, S. E. R.; BZUNECK, J. A. Recompensas externas e a motivação dos estudantes: um estudo exploratório, 2006. No prelo.

LEPPER, M. R.; HENDERLONG, J. "Play" into "work" and "work" into "play": 25 years of research on intrinsic versus extrinsic motivation. In: SANSONE C.; HARACKIEWICZ, J. (Ed.), Intrinsic and extrinsic motivation: The search for optimal motivation and performance. San Diego: Academic Press, 2000. p.257-307.

LEPPER, M. R.; HENDERLONG, J.; IYENGAR, S. S. Intrinsic and Extrinsic Motivational Orientations in the Classroom: Age Differences and Academic Correlates. Journal of Educational Psychology, Arlington, v.97, n.2, p.184-196, 2005.

MCLNENEY, D. M.; ETTEN, S. V. Big Theories Revisited. Connecticut: Age Publishing, 2004.

NEWBY, T. J. Classroom motivation: strategies of first-year teachers. Journal of Educational Psychology, Arlington, v.83, n.2, p.195-200, 1991.

PINTRICH, P. R; DE GROOT, E. V. Motivational and self-regulated learning components of classroom academic performance. Journal of Educational Psychology, Arlington, v.82, n.1, p.33-40, 1990.
REEVE, J.; DECI, E. L.; RYAN, R. M. Self Determination Theory: A dialectical framework for understand sociocultural influences on student motivation. In: MCINERNEY, D. M.; VAN ETTEN, S. (Ed.). Big Theories Revisited. Connecticut: Age Publishing, 2004.

SALISBURY-GLENNON, J. D.; STEVENS, R. J. Addressing preservice teachers' conceptions of motivation. Teaching and Teacher Education, New York, v.15, n.7, p.741-752, 1999.

STIPEK, D. J. Motivation and instruction In: BERLINER, D. C.; CALFEE, R. C. (Ed.) Handbook of Educational Psychology. New York: Simon \& Schuster Macmillan, 1996. p.63-84.

STIPEK, D. J. Motivation to Learn: From Theory to Pratice. Englewood Cliffs: Prentice Hall, INC, 1998

TOLLEFSON, N. Classroom Aplications of Cognitive Theories of Motivation. Educational Psychology Review, New York, v.12, n.1, p.63-83, 2000.

VAN DE VIJVER, F. J. R.; HAMBLETON, R. K. Translating tests: some pratical guidelines. European Psychologist, London, v.1, n.2, p.89-99, 1996. 